C-B and C-A groups $[t(206)=5.2, p<.01]$. The relative ordering of the groups is in agreement with expectations from the two-phase conception (cf. Martin, 1965).

The results indicate that at LIRS there is no effect of DOL on transfer performance. Two previous experiments that involved comparable C-B and A-Br paradigms (Jung, 1962; Postman, 1962) minimized intralist response similarity and have also failed to report a significant DOL transfer effect. $A$ third study that included the C-A and $\mathrm{A}-\mathrm{Br}$ paradigms (Schulman, 1967) used high-frequency nouns as response terms, a list which presumably would constitute LIRS items, and found no DOL effect. Dean \& Kausler (1964) minimized IRS and reported poorer transfer performance with increased DOL for the C-B paradigm. It is interesting to note that the present study, Postman (1962), and Jung (1962), each of which contained comparable C-B paradigms, utilized words as stimuli for the transfer task, whereas Dean \& Kausler (1964) used nonsense syllables. Dean \& Kausler (1964) suggest the possibility that backward associations from first-list learning increase more with greater DOL when nonsense syllables serve as stimuli than when words serve as stimulus terms. Except for the Dean \& Kausler (1964) study, the literature is consistent in reporting no transfer effect of DOL with transfer-task response terms of low intralist similarity.

Turning to HIRS, with increased DOL, highly similar response units would be expected to lead to relatively better transfer performance than LIRS units because of the greater importance of response differentiation. Figure 2 shows that the expected DOL by IRS interaction was obtained. However, it would seem that Ss serving in the $C-A$ and $B r-A$ paradigms would have had less opportunity to become familiar with the terms during first-list learning that were to later become transfer-task responses. For this reason, the IRS by DOL interaction was expected not to be as potent for these Ss. The subsequent response terms were on the stimulus side during first-list learning for these paradigms, and consequently, $S$ could have engaged in stimulus selection or, at the very least, did not need to learn these units as well as they would have needed to if they had been initial-task response terms. In addition, it took less trials for Ss in Paradigms C-A and $\mathrm{Br}-\mathrm{A}$ to attain the first-list acquisition criterion, affording these $S$ s even less opportunity for familiarization with the critical items. A possible explanation of the failure to find a Paradigm by IRS by DOL interaction is that the similar units were, indeed, so similar that even when they were placed on the stimulus side $S$ needed to learn to clearly distinguish between these verbal units in order to reach the $6 / 6+1$ acquisition criterion. Subsequently, on the second task, where Ss had to transfer stimulus differentiation to response learning and to response differentiation, prior exposure to the highly similar material at the severe acquisition criterion led to as much relative facilitation in performance as the conditions in which the critical items had been response terms.

When number of trials spent on first-list learning was covaried, there were no changes in the results of the transfer-task analyses. In addition, the C-D control groups (see Fig. 2) did not show differential transfer performance as a function of degree of first-list learning. These results suggest that, within the limits of training manipulated in the present study, there was no differential effect of learning-to-learn and warm-up. The control groups, however, are probäbly inappropriate. They differ in meaningfulness from that used in the experimental paradigms, and in addition, they failed to control for the similarity conditions. As a further note of caution, during first-list training, similarity was manipulated on the stimulus side for Paradigms $\mathrm{C} \cdot \mathrm{A}$ and $\mathrm{Br}-\mathrm{A}$. Thus, initial task IRS and intralist stimulus similarity, as well as stimulus vs response-term meaningfulness were varied in the comparison of the $C-B$ and $\mathrm{A}-\mathrm{Br}$ paradigms with Paradigms $\mathrm{C}-\mathrm{A}$ and
Br-A. Paradigms, however, did not interact as a variable in the transfer results, indicating that the IRS by DOL interaction held for all groups.

\section{REFERENCES}

CIEUTAT, V. J., STOCKWELL, F. E., \& NOBLE C. E. The interaction of ability and amount of practice with stimulus and response meaningfulness (m, $\left.\mathrm{m}^{3}\right)$ in paired-associate learning. Journal of Experimental Psychology, 1958, 56, 193-202.

DEAN, M. G., \& KAUSLER, D. H. Degree of first-list learning and stimulus meaningfulness as related to transfer in the $A \cdot B, C-B$ paradigm. Journal of Verbal Learning \& Verbal Behavior, $1964,3,330-334$.

JUNG, J. Training a function of degree of first-list leaming. Joumal of Verbal Learning \& Verbal Behavior, 1962, 1, 197-199.

MARTIN, E. A. Transfer of verbal paired-associates. Psychological Review, 1965 72, 327-343.

NEWMAN, S. E., \& BUCKHOUT, R. S-R and R-S learning as functions of intra-list similarity. American Joumal of Psychology, 1962, 75, 429-436.

POSTMAN, $L$. Transfer of training as a function of experimental paradigm and degree of first-list learning. Journal of Verbal Learning \& Verbal Behavior, 1962, 1, 109-118.

SCHULMAN, R. M. Paired-associate transfer following early stages of list 1 leaming. Journal of Experimental Psychology, 1967, 73, 589-594.

NOTE

1. This investigation was supported by Public Health Service Research Grant MH 14017.

\title{
On the relative usefulness of monaural and binaural cues in locating sound in space
}

\section{ROBERT A. BUTLER, University of Chicago, Chicago, Ill. 60637}

The cues for locating sound in the vertical plane are predominantly monaural; binaural cues are available for horizontal plane localization. Ss, required to locate repetitive noise bursts originating in the vertical plane, performed significantly above chance level $(p<.005)$. Performance in locating sound sources in the horizontal was significantly superior to that recorded for the vertical plane $(p<.005)$. These results support the claims that relatively accurate sound localization can take place when only monaural cues are available. But the significant contribution of binaural cues is clearly evident if the angle between sound sources is made small.
Lately, there has been a flurry of interest in the ability of man to locate sound solely on the basis of monaural cues (Batteau, 1968; Bauer et al, 1966; Butler \& Naunton, 1967; Fisher \& Freedman, 1968a, b; Perrott \& Elfner, 1968). The way these experiments are usually run is that the listener is asked to locate sounds with and without one ear being blocked. And, indeed, when the angle between loudspeakers is reasonably large, Ss can locate as accurately listening with one as they can with two ears (Fisher \& Freedman, 1968a). This is interesting. Apparently, spectral cues serve well the listener when he is forced to rely on one ear. There may be still other cues operating. Batteau (1968) believed that the contours of the pinna transformed the sound into a configuration of repetitive wavefronts. He was able to demonstrate, on an enlarged model of the pinna, that the temporal intervals between 
successive wavefronts changed systematically with different locations of the sound source. Fisher \& Freedman (1968a) suggest that binaural cues are neither necessary nor sufficient for locating sound in space. Their data support them. The implication here is that one ear is just as good as two in the sound-localization task. This is difficult to accept. Granted, there may be no apparent difference between monaural and binaural performance if the task is simple. In the Fisher and Freedman study, for example, the loudspeakers were $22.5 \mathrm{deg}$ apart. But if the task is made more demanding, the expectation that listeners would still perform as accurately when listening monaurally as when listening binaurally would probably not be shared iwidely. There is so much data available-psychophysical, neurophysiological, and neuroanatomical-attesting to the elegance of the binaural mechanisms that one would be hard-pressed to convince another that these mechanisms are superfluous.

Yet, it appeared worthwhile to look at this problem more closely. There are at least two approaches. One is to decrease the angle between loudspeakers and compare performance when one ear is blocked to that when neither ear is blocked. If, however, monaural performance should turn out to be inferior, one could argue that the listener was experiencing a unique pattern of central nervous system stimulation. Neurons presumably important for sound localization and which are normally activated binaurally would be receiving input from only one ear. This is an unusual listening situation for normal-hearing persons; the data would be difficult to interpret unequivocally. Another method is to compare localization performance in the horizontal plane with that in the vertical. Binaural cues are available in the former; no

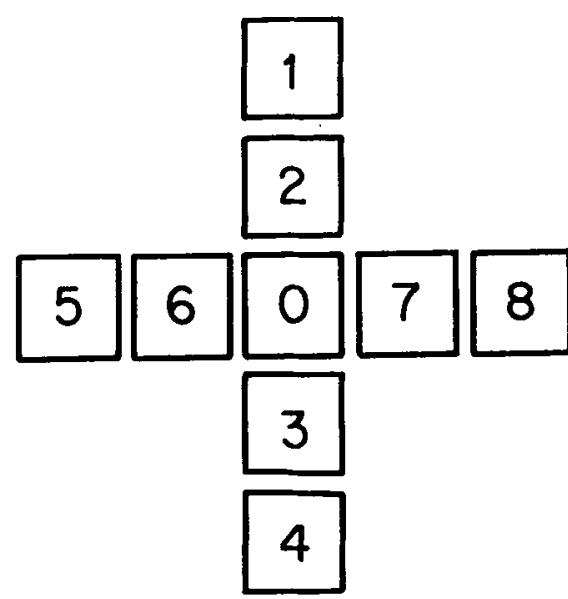

Fig. 1. A diagram of the loudspeaker arrangement. apparent binaural cues are available in the latter. The second approach was followed in the present study.

Twenty Ss with normal hearing were asked to call out the number of the loudspeaker from which they thought the sound originated. The loudspeakers, 4-in

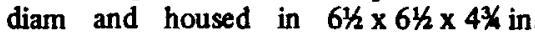
wooden cabinets, were arranged vertically and horizontally as shown in Fig. 1. The numbers were painted black on white cloth glued to the front of the loudspeaker cabinet. The listener was seated at a distance of $72 \mathrm{in.}$ and the angle between loudspeakers, center to center, was $6 \mathrm{deg}$. The stimuli were broad-band noise bursts of $10 \mathrm{msec}$ duration, fast rise-fall time, and each separated from the other by $150 \mathrm{msec}$ of silence. The sensation level generated by each loudspeaker was systematically varied. Its average was $30 \mathrm{~dB}$; its range extended from 24 to $36 \mathrm{~dB}$ in steps of $2 \mathrm{~dB}$. Each of the nine loudspeakers was represented 10 times within a quasi-random presentation order. The noise bursts continued until $S$ made a localization judgment. Ss were instructed to keep their heads firmly against the headrest and to refrain from moving their heads during presentation of the stimuli. Insofar as one could confirm by visual monitoring, the Ss followed strictly these instructions.

The distribution of error sizes was taken as the index of localization proficiency. An error size of $\mathbf{0}$ was recorded if $S$ correctly identified the loudspeaker that was generating the noise bursts. An error size of $1,2,3$, or 4 was recorded if his judgment was $1,2,3$, or 4 loudspeakers removed from the correct loudspeaker, respectively. When the sound was generated by Loudspeaker No. 0 , the nule followed was to record a horizontal error if another loudspeaker in the horizontal plane was chosen; a vertical error was recorded if $S$ called out another loudspeaker in the vertical plane. And, if a sound was generated by one of the other loudspeakers in the horizontal plane, but was identified as originating in the vertical plane, an error in the horizontal plane was recorded. The reverse situation was handled comparably. In this kind of choice situation, error sizes are Poisson distributed.

\section{RESULTS}

The results are summarized in Fig. 2. A chi-square test of goodness of fit indicated that Ss were localizing sound sources in the vertical plane significantly different from chance level $(\mathrm{p}<.005)$. But it is equally clear from Fig. 2 that performance in locating sound sources in the horizontal plane was much superior to that recorded for vertical-plane localization $(p<.005)$. Rarely were sound sources in the vertical plane perceived as emanating from the

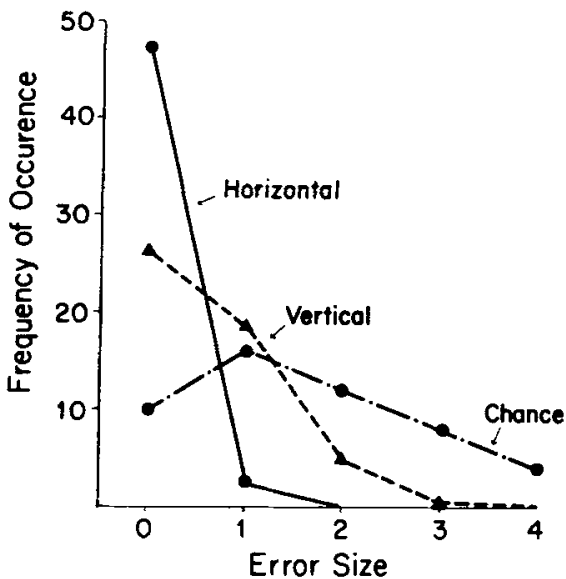

Fig. 2. The distribution of error sizes calculated for chance performance and observed for performances in the vertical and horizontal planes.

horizontal plane, and vice versa. All errors arising when the sound originated from Loudspeaker No. 0 were errors in the vertical plane.

\section{COMMENTS}

Assuming that binaural cues are minimal when locating sound in the vertical plane, these data are consistent with earlier findings that relatively accurate localization of sound in space can occur without their benefit. This, however, should not becloud the finding that binaural cues are essential for proficiency in performance when the localization task is demanding. Sound sources $6 \mathrm{deg}$ apart were localized significantly more accurately when they were in the horizontal plane rather than in the vertical.

\section{REFERENCES}

BATTEAU, D. W. Listening with the naked ear. In S. J. Freedman (Ed.), The neuropsychology of spatially ariented behavior. Homewood, Ill.: Dorsey Press, 1968. Pp. 109-133.

BAUER, R. W., MATUZSA, J. L., BLACKMER, R. F., \& GLUCKSBERG, S. Noise localization after unilateral attenuation. Journal of the Acoustical Society of America, 1966, 40, 441-444.

BUTLER, R. A., \& NAUNTON, R. F. The effects of stimulus sensation level on the directional hearing of unilaterally deafened persons. Journal of Auditory Research, 1967, 7, 15-23.

FISHER, H. G., \& FREEDMAN, S. J. Localization of sound during simulated unilateral conductive hearing loss. Acta Oto-Laryngologica, 1968, 66 , 213-220.

FISHER, H. G., \& FREEDMAN, S. J. The role of the pinna in auditory localization. Joumal of Auditory Research, 1968, 8, 15-26.

PERROTT, D. R., \& ELFNER, L. F. Monaural localization. Journal of Auditory Research, 1968, 8, 185-193.

1. The author appreciates the loan of loudspeakers and sound cage by Zenith Radio Corporation.

2. This investigation was supported in part by a Public Health Service Research Career Development Award NINDS. 